\title{
Choosing equipment for treating genital warts in genitourinary medicine clinics
}

\author{
Anne Scoular
}

Anogenital warts represent a major therapeutic problem in genitourinary medicine. A wide range of treatment modalities is available (the usual indication that none is ideal). This therapeutic problem is not new; in the sixth century, Dionysius graphically described treatment of genital warts: "The surgeons spared neither iron nor fire, and were not moved to pity by the cries of the patients". Both of these treatment modalities remain in existence today, although fortunately they have been modified since the sixth century!

The long-term natural history of genital wart lesions has been poorly studied, but it is the experience of most clinicians that the majority of patients with genital warts are managed easily with simple chemo-destructive measures such as trichloracetic acid or podophyllin. A significant minority of patients will, however, fail to respond to such simple measures. Keratinised warts on dry skin, such as the shaft of the penis or perianal area, may often respond poorly; there may be virological and immunomodulatory reasons for this which are, at present, poorly understood.

Patients with recalcitrant warts generally require more aggressive treatment. A range of surgical techniques is available for treatment of this group of patients, including scissor excision, electrosurgery, laser surgery and cryosurgery. These all have advantages and disadvantages. Efficacy between the different modalities is difficult to compare, owing to paucity of randomised comparative studies. Those which exist often had high drop-out rates, variable duration of follow-up, and disparate clinical features. ${ }^{1-5}$ In the absence of more data, it would be reasonable to conclude that no one modality is the treatment of choice. All require the use of appropriate equipment, broad comparative features of which are summarised in table 1 and in the remainder of this article.

Scissor excision

One of the simplest and cheapest surgical techniques

Department of Genitourinary Medicine, The Middlesex Hospital, London W1N 8AA, UK

Anne Scoular for treating recalcitrant genital warts is scissor excision, first described by Thomson and Grace in $1978^{6}$ as a treatment for anal warts. It is, however, readily applicable to lesions on the vulva and penis as well. Ideally suited lesions are pedunculated warts, over $3 \mathrm{~mm}$ in diameter. Small, flat warts are difficult to excise. Infiltration of sub-epidermal lignocaine $1 \%$ and adrenaline 1:200,000 allows separation of warts and identification of individual lesions. The use of adrenaline is contraindicated on the penis. Prior application of EMLA cream under plastic film occlusion for 15 minutes is used by some clinicians.

Warts are excised across the base, using finetoothed dissecting forceps and pointed curved scissors, creating small elliptical skin deficits. Bleeding is usually minimal, and can be controlled by pressure or by light electrodesiccation (see Electrosurgery), if available. If clinically indicated, histological examination of any excised lesions may be performed. Healing is usually excellent within 10-14 days, with minimal scar tissue formation.

\section{Cryotherapy}

Cryotherapy is the application of cold with the object of targetted therapeutic tissue destruction. Cellular necrosis occurs both directly, due to formation of intracellular ice crystals, and indirectly, as a result of micro-circulatory failure. Studies with thermocouples have contributed to research and knowledge about rational cryosurgical techniques. ${ }^{7}$ There is no general agreement on the optimal temperature required to induce cell death, but it is likely to be $-50^{\circ} \mathrm{C}$ or lower. ${ }^{8}$ There is a marked subdermal temperature gradient below a cryotherapy probe, with the temperature ranging from about $-120^{\circ} \mathrm{C}$ at the skin surface to as warm as $-26^{\circ} \mathrm{C}$ just a few millimetres deeper. It is possible to calculate the depth of both the $0^{\circ} \mathrm{C}$ and $-25^{\circ} \mathrm{C}$ isotherms for a given sized probe, thus guaranteeing an adequate depth of freezing. ${ }^{9}$ This is clearly important when treating dermatological malignancies with cryotherapy but is less crucial in treating genital warts.

The main criterion used to determine the effectiveness of the freeze is formation of an ice ball 1-2 mm beyond the periphery of the lesion. This is initially rapid, but finite, as ice begins to act as an insulator and equilibrium is reached. It is important to maintain 
Table 1 Comparative evaluation of treatment modalities for genital warts

\begin{tabular}{|c|c|c|c|c|}
\hline Treatment modality & Scissor excision & Cryosurgery & Electrosurgery & Laser surgery \\
\hline $\begin{array}{l}\text { Efficacy (\% lesions cured } \\
\text { at } 3 \text { months) }\end{array}$ & $77-85 \%$ & $63-79 \%$ & $78-90 \%$ & $43-95 \%$ \\
\hline $\begin{array}{l}\text { Local anaesthetic required } \\
\text { Physician training } \\
\text { requirement }\end{array}$ & $\begin{array}{l}\text { Yes } \\
\text { Intermediate }\end{array}$ & $\begin{array}{l}\text { No } \\
\text { Low }\end{array}$ & $\begin{array}{l}\text { Yes } \\
\text { Intermediate }\end{array}$ & $\begin{array}{l}\text { Yes } \\
\text { High }\end{array}$ \\
\hline $\begin{array}{l}\text { Hazards } \\
\text { Purchasing costs } \\
\text { Maintenance costs } \\
\text { Additional uses }\end{array}$ & $\begin{array}{l}\text { Negligible } \\
£ 70-100 \\
\text { Low } \\
\text { Skin biopsy }\end{array}$ & $\begin{array}{l}\text { Low } \\
\text { f500-2,000 } \\
\text { Intermediate } \\
\text { Few }\end{array}$ & $\begin{array}{l}\text { Intermediate } \\
\text { f } 400-16,000 \\
\text { Low } \\
\text { 1. Loop diathermy } \\
\text { cervical conisation } \\
\text { 2. Management of } \\
\text { minor skin lesions }\end{array}$ & $\begin{array}{l}\text { High } \\
\text { f15,000-30,000 } \\
\text { High } \\
\text { 1. Management of CIN } \\
\text { 2. Management of minor } \\
\text { skin lesions } \\
\text { 3. Eradication of intra- } \\
\text { urethral warts }\end{array}$ \\
\hline
\end{tabular}

freezing for an adequate length of time, depending on the size of the lesion and anatomical site. Zacarian ${ }^{10}$ recorded temperatures $5 \mathrm{~mm}$ below a $16 \mathrm{~mm}$ cryoprobe of $0^{\circ} \mathrm{C}$ after 30 seconds, $-8^{\circ} \mathrm{C}$ after 60 seconds and $-23^{\circ} \mathrm{C}$ after a 120 second freeze.

Further cellular injury also occurs during thawing, particularly if this occurs slowly. ${ }^{11}$ Two freeze-thaw cycles separated by 5 minutes are recommended for treatment of basal cell carcinoma ${ }^{12}$ and hence are likely to be more effective for wart treatment than a single freeze. Destruction of epidermal cells is associated with vesiculation which is occasionally haemorrhagic; sloughing and healing follow.

Several convenient cryounits have been developed, most using either nitrous oxide $\left(\mathrm{N}_{2} \mathrm{O}\right)$, carbon dioxide $\left(\mathrm{CO}_{2}\right)$ or liquid nitrogen $\left(\mathrm{N}_{2}\right)$ as the refrigerant. There are two generic types of unit:

(1) A hand-held insulated and pressurised steel flask, with a control valve, to which a range of sprays and probes may be fitted (fig 1). These are refillable and operate on liquid $\mathrm{N}_{2}$. As the spray jet is pressurised, the patient may experience more discomfort during treatment compared with the use of a cryoprobe. In some situations, cryosprays may not be accurate enough, for example with urethral meatal warts. This device does, however, achieve an effective freeze and cross infection risks are minimised. Liquid $\mathrm{N}_{2}$, evaporates and the units have to be refilled frequently. Adequate supplies of liquid $\mathrm{N}_{2}$ should be readily available on site, as the need for frequent delivery significantly increases running costs.

(2) Closed cryotherapy systems, operating as a continuous flow of either $\mathrm{CO}_{2}$ or $\mathrm{N}_{2} \mathrm{O}$ through flexible cables to a cryoprobe tip, which is usually operated by a gun (fig 2). A range of interchangeable tips is available, all of which are autoclavable. Some guns are fitted with both freezing and thawing triggers, which offers the advantage of better control, particularly of defrosting time. More sophisticated cryosurgery units are available with thermocouple attachments which monitor temperature at the tip of the probe. This is particularly important when treating either dermatological or gynaecological neoplasia. It is, however, unlikely that the increased expense of thermocouple units is justifiable in the setting of a genitourinary medicine clinic, particularly as cryotherapy is no longer considered to achieve an adequate depth of treatment for large, higher grade cervical intraepithelial neoplasia (CIN) lesions. ${ }^{13}$

Choice of unit Pressurised liquid nitrogen canisters are convenient for most uses. There are some situations (such as in treating non-neoplastic conditions of the cervix such as urethral meatal warts and patients who cannot tolerate cryosprays), where a cryoprobe is a better alternative. Large clinics may opt to purchase both devices. Otherwise, a reasonable compromise would be the purchase of a cryospray with several probe attachments.

\section{Electrosurgery}

Electrosurgical equipment has been an invaluable surgical aid for almost a century now, but unfortunately much of the nomenclature surrounding its use remains confusing and pseudoscientific. For the clinician, this creates difficulties with selection of equipment, the basic function of which is simply to destroy tissue by heating. Starting from fundamental electrical principles, this section aims to clarify terminology and facilitate rational choice of equipment best suited to clinical needs. Electrical energy may be supplied by either direct current or alternating current (see fig 5). Direct current circuitry is simple, electrons flowing from a negative to a positive electrode. When this circuit includes the patient, current flow is necessarily low; this system is used for Galvanic surgery, including electrolysis and iontophoresis (used in treating hyperhidrosis). Direct current is also used in electrocautery; in this situation the patient is not part of the electrical circuit. Current flow is high, generating heat in a resistance element (similar to that in an electric fire) which can then be used to produce thermal damage to tissues. Electrocautery can be used in some situations (such as in 


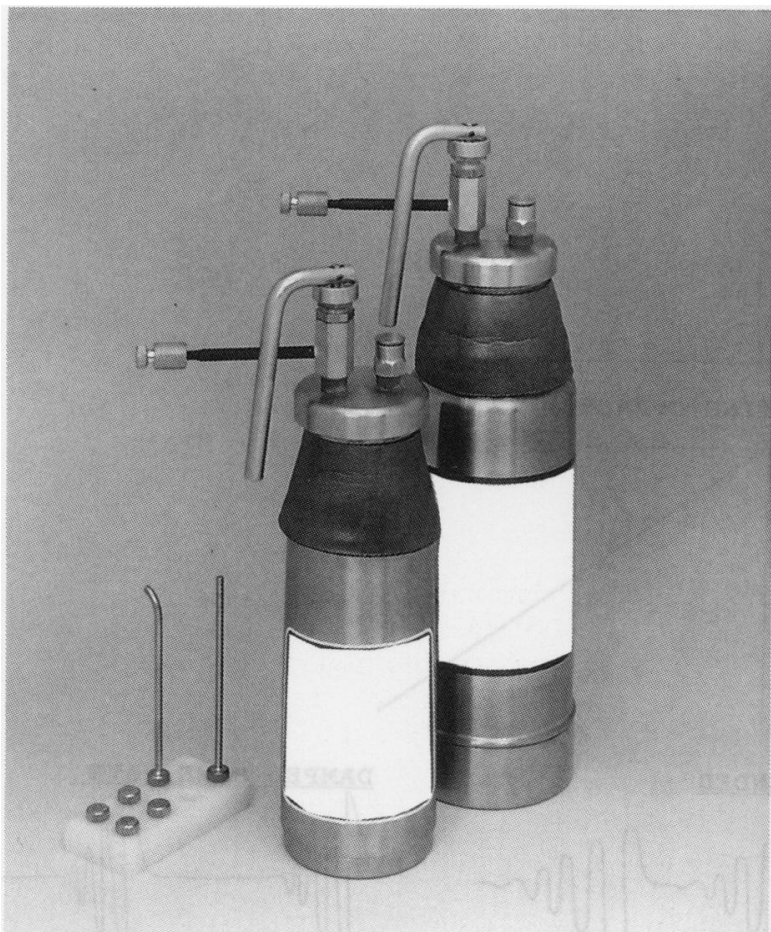

Figure 1 A typical hand-held cryospray showing a range of interchangeable probes.

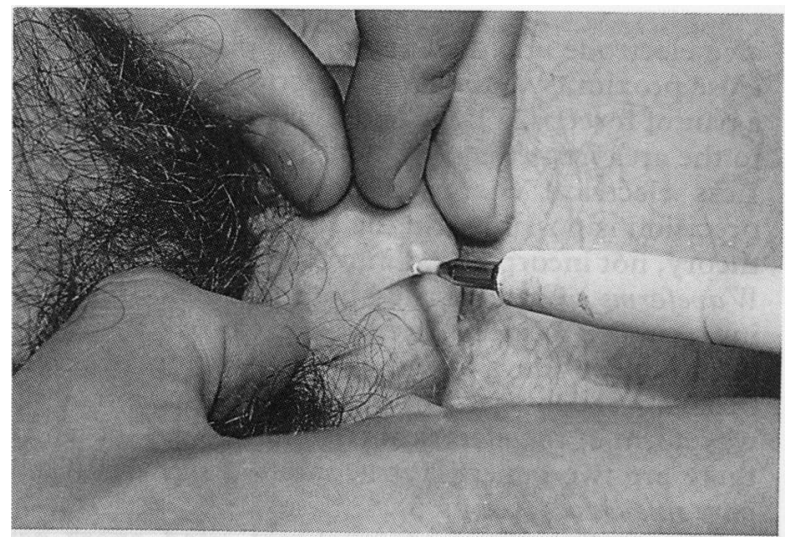

Figure 2 A typical cryotherapy probe in use for penile shaft warts.

fluid environments or on non-conductive tissue such as nail, bone and cartilage), when more sophisticated electrosurgery is unsuitable, but cosmetic results are unpredictable and sometimes unsatisfactory. The term cautery should be used only for such conducted heat transfer devices, but it is often inappropriately used for other forms of electrosurgery.

Alternating current is the mainstay of modern

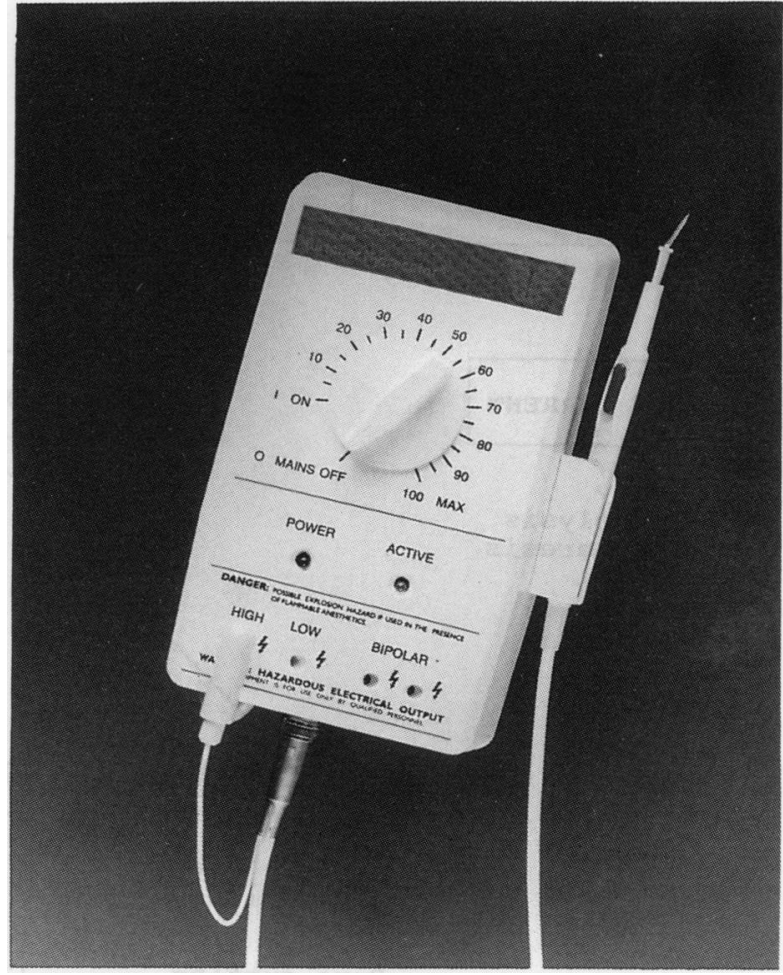

Figure 3 A low power electrosurgical unit with optional monopolar or bipolar facilities.

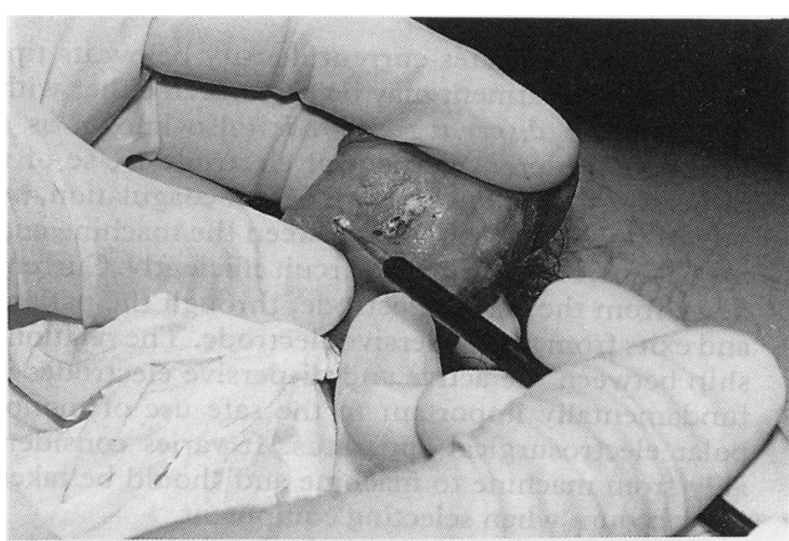

Figure 4 Electrodesiccation of keratinised penile shaft warts using a low power monopolar unit.

electrosurgical units, which boost standard mains electricity to very high voltage and frequency levels, reducing amperage; this current passes through the patient and can be made to produce heat where current density is greatest. There are two basic ways in which high frequency current can be transferred through the patient:

(1) Monopolar (monoterminal) where a single active 


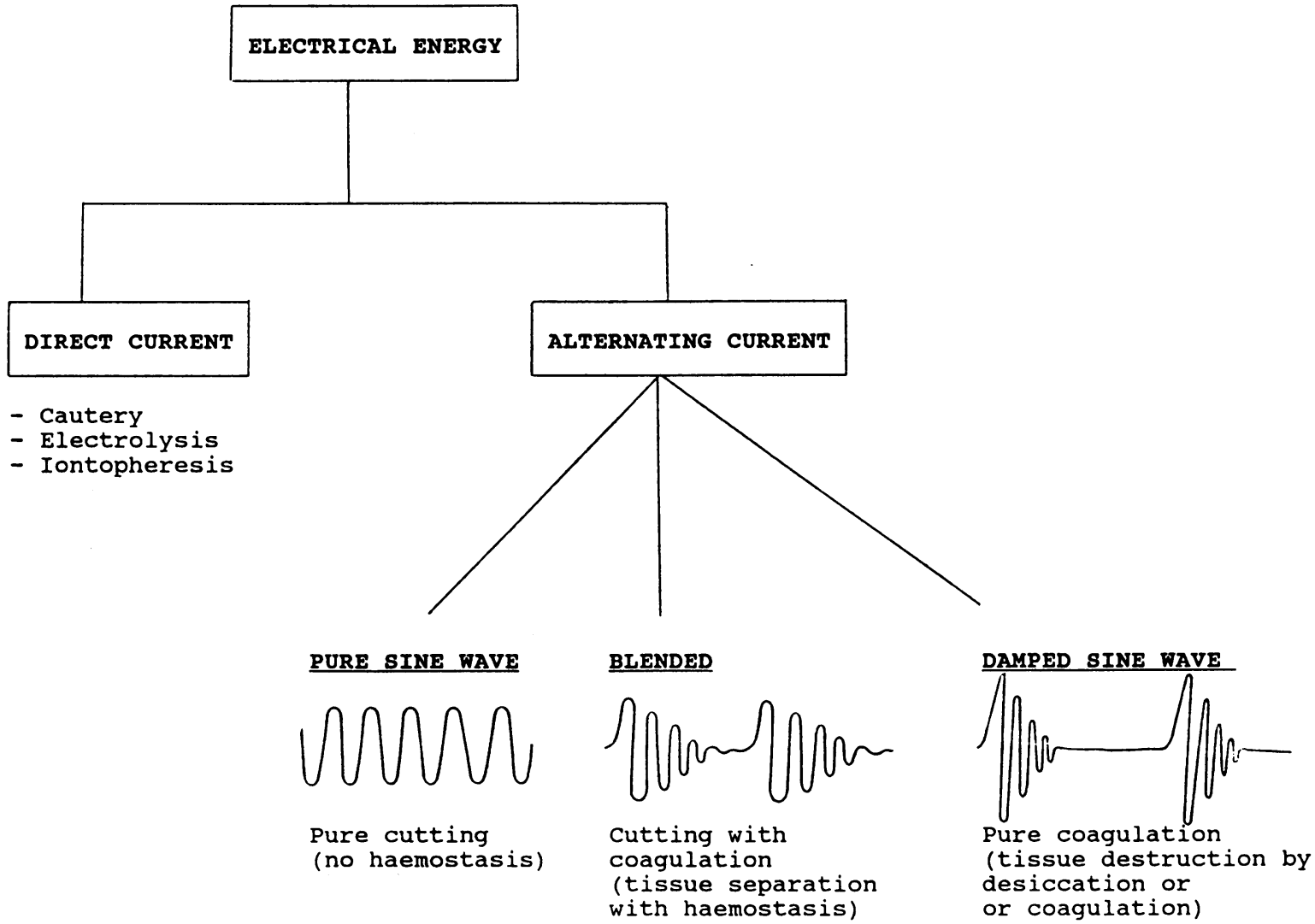

Figure 5 Classification of electrosurgical techniques.

electrode concentrates current density below its tip. Monopolar treatment may be performed either with or without a dispersive electrode (also known as a ground, indifferent or neutral electrode). Use of a dispersive plate allows more efficient coagulation, by providing a direct contact between the machine and the patient, completing the circuit efficiently. Current flows from the active electrode, through the patient and exits from the dispersive electrode. The relationship between the active and dispersive electrodes is fundamentally important to the safe use of monopolar electrosurgical apparatus. It varies considerably from machine to machine and should be taken into account when selecting equipment.

There are three types of circuitry, grounded, referral-to-ground ( $R F$ earthed) and isolated. The isolated and referral-to-ground systems are safer in the event of equipment malfunction. As stated above, monopolar treatment may be carried out without the use of a dispersive electrode. This system completes the circuit to the machine by a much less direct route, thus necessitating high voltages and therefore low current flow. Hence it is suitable only for light superficial coagulation.

(2) Bipolar (biterminal)

Bipolar treatment eliminates the problem of a disper- sive electrode at a distant site, by placing it in very close proximity to the active electrode, commonly as a pair of forceps. The primary tissue effect is limited to the area immediately between the two electrodes. Less electrical energy is required, much greater precision is possible and the rest of the patient is, in theory, not incorporated into the circuit.

Waveforms Concentrated high frequency alternating current produces tissue changes below the region of the electrode tip with accompanying heat and mechanical damage. The tissue effects depend on the waveform of the electrical current applied, of which there are two generic types: damped sine waves and pure sine waves (see fig 5).

The earlier types of machines used spark-gap generators and vacuum tubes to produce these waveforms, but most have now been superseded with more controllable electronic circuitry, producing finely tuned concentrated energy within the waveform.

\section{Electrosurgical techniques}

The terminology used to describe the tissue effects of high frequency electrical energy is diverse and confusing, but the basic underlying principle is simple, that is, heat production at a localised point in the 
tissues, due to entry of high frequency currents. Different terms are used to describe electrosurgical techniques; the first three differ more in degree than in nature. Definitions are as follows:

(1) Electrofulguration

Derived from Latin "fulgur" (lightning). This technique requires high voltage, lower amperage current which sparks across an air gap between the electrode to the tissue, without touching it. This produces very superficial charring, with very little dermal damage and rapid healing.

\section{(2) Electrodesiccation}

Is essentially the same as electrofulguration, except that the treatment electrode is in contact with the tissue, generating local heat and tissue dehydration at a deeper level.

\section{(3) Electrocoagulation}

Is characterised by more marked destruction of tissue using a higher amperage, usually requiring use of a dispersive electrode.

\section{(4) Cutting}

This modality is usually blended with some damped, coagulating current. An increasing application of this technique is its use in loop diathermy cervical cone biopsy.

Hazards The physician should be aware of all the potential hazards of electrosurgery, which include burns, channelling of current along neurovascular structures (particularly likely in the penis at higher power settings), fire, electrocution, interference with cardiac pacemakers and explosion.

\section{Application to treatment of genital warts (figs 3, 4)}

Use of electrosurgery on skin requires a low power output which will minimise tissue damage. Intensive coagulation produces cell destruction which is always more extensive than superficial inspection suggests. This may lead to delayed healing, secondary bleeding when the slough separates about 10-14 days after treatment, infection and scarring. For very localised, delicate application of electrosurgery, a bipolar unit is ideal. Flat warts can be treated with superficial electrodesiccation and necrotised epithelium wiped off subsequently with a gauze swab. Penetration below the upper dermis generally leads to crater formation and is to be avoided. Very large condylomata acuminata sometimes occur in the perivaginal or perianal areas. These may be removed very efficiently using a cutting current followed by light electrodesiccation to the bases. Some gynaecologists are now using loop diathermy excisional cone biopsy as a combined diagnostic and therapeutic tool in management of women with CIN. ${ }^{14}{ }^{15}$ Although this is still controversial, loop diathermy conisation techniques are becoming increasingly used and it is likely that genitourinary physicians running a colposcopy service may wish to choose diathermy equipment with this capability, which requires a cutting output.

In summary, a low power diathermy unit (rated output below 100 watts) with bipolar electrodes will provide the delicacy and precision required for destruction of small genital warts without scar tissue formation. However, some physicians may require the facilities of cutting diathermy; this is not yet possible with bipolar forceps in their current design. It is offered by several (but not all) monopolar low power machines. Several machines offer both monopolar and bipolar outputs.

\section{Laser}

The application of laser technology to medicine has led to important therapeutic advances, many in specialties closely allied to genitourinary medicine, including gynaecology, urology and dermatology, so it would be somewhat surprising if lasers did not have a place in genitourinary medicine. However, the important question is whether laser treatment should be chosen in preference to other treatment modalities for recalcitrant genital warts.

Laser (Light Amplification by Stimulated Emission of Radiation) possesses three properties which distinguish it from ordinary light. They are:

(1) Coherence: All the light energy particles (photons) travel in phase with each other in time and space and form a wavefront. (2) Collimation: The light travels in a completely straight path with very little divergence. (3) Monochromaticity: All light produced by lasers is of the same wavelength. The effects of laser light on tissue depend on how much of the light beam is absorbed by the exposed tissue and thereby converted to heat energy. The higher the absorption of laser energy by the tissue, the most superficial is the penetration of the beam. Laser effects on tissue depend on:

(a) Type of laser used: each laser emits its own characteristic wavelength of light which has specific tissue transmission characteristics; for example $\mathrm{CO}_{2}$ laser light cannot be transmitted through fluids. The degree of absorption by any tissue is inversely proportional to its depth of penetration.

(b) Power density: this concept refers to the concentration of laser energy within the treated area. It can be varied by focusing or defocusing the laser beam, using a system of lenses. Power density is the power output of the laser (in watts) divided by the size of the focal spot on the tissue. Both can be varied, within a certain range determined by the machine.

(c) Length of time for which the target tissue is exposed to the laser: many lasers can deliver either a continuous beam or "pulses" as short as $5 \mathrm{~ms}$ which allows the maximum power output of the laser to be used to advantage, minimising excessive damage to the tissues.

Much development work in laser technology lies in 
Table 2 Properties and uses of $\mathrm{CO}_{2}$, Argon and ND : YAG lasers

\begin{tabular}{|c|c|c|c|}
\hline Laser type & $\mathrm{CO}_{2}$ & Argon & $N d: Y A G$ \\
\hline Wavelength (nm) & 10,600 & 500 & 1064 \\
\hline Colour & Infra-red & Blue-green & Infra-red \\
\hline Tissue reaction & $\begin{array}{l}\text { Highly absorbed by } \\
\text { cellular water. } \\
\text { Independent of tissue } \\
\text { colour. }\end{array}$ & $\begin{array}{l}\text { Intermediate scattering } \\
\text { and absorption. } \\
\text { Preferential absorption } \\
\text { by red/black pigments. }\end{array}$ & $\begin{array}{l}\text { Highly scattered and } \\
\text { absorbed over a diffuse } \\
\text { area some preferential } \\
\text { absorption by dark } \\
\text { pigments. }\end{array}$ \\
\hline $\begin{array}{l}\text { Depth of penetration } \\
\text { (mm) }\end{array}$ & $0 \cdot 1-0.5$ & $0 \cdot 5-2$ & $2-6$ \\
\hline Surgical function & Cutting, vaporisation & $\begin{array}{l}\text { Coagulation, cutting and } \\
\text { vaporisation }\end{array}$ & $\begin{array}{l}\text { Mainly coagulation (newer } \\
\text { sapphire contact probes } \\
\text { allow cutting and } \\
\text { vaporisation) }\end{array}$ \\
\hline Transmission system & Articulated arm & Fibreoptic & Fibreoptic/contact probes \\
\hline
\end{tabular}

improving devices for delivery of the laser beam. At present, these are usually either a series of "articulated arms", (refined by incorporation of a micro-manipulator "joy stick" where sensitive tactile control is required), or a flexible fibreoptic device. Although flexible fibreoptics are more easily manipulated, their two main disadvantages are that some laser wavelengths (including the commonly used $\mathrm{CO}_{2}$ laser) are not transmittable via traditional glass fibres and, secondly, some loss of coherence occurs in the laser beam during transmission down the fibre. The $\mathrm{CO}_{2}$, neodymium: YAG and argon lasers are all suitable for treating genital warts; experience is most extensive with the $\mathrm{CO}_{2}$ laser.

Table 2 compares the three lasers in their physical properties and tissue effects. The $\mathrm{CO}_{2}$ laser is widely used in gynaecology and has found frequent application, coupled with the colposcope, in ablative or excisional treatment for CIN. This led naturally to extension of its use to treatment of vulval disease, including condylomata acuminata. Careful manipulation of the $\mathrm{CO}_{2}$ laser under colposcopic control achieves a supremely accurate depth of tissue destruction, varying between 0.1 and $0.5 \mathrm{~mm}$. Portable, hand-held $\mathrm{CO}_{2}$ lasers have also been developed for use in dermatology, although these do not seem to be any less unwieldy than those with articulated arms. The $\mathrm{CO}_{2}$ laser is a poor haemostatic, and although bleeding is uncommon during its use, if it does occur it is best controlled by direct pressure.

The neodymium: YAG laser penetrates more deeply than the $\mathrm{CO}_{2}$ laser. Care is, therefore, needed to avoid overtreatment, with the consequences of delayed healing and formation of scar tissue. Urologists have used the YAG laser in transurethral bladder surgery for many years. Unlike the $\mathrm{CO}_{2}$ laser, minimal tissue vaporisation occurs with the YAG laser and condylomata need to be gently removed with forceps after being coagulated.

Experience with the argon laser lies mainly in the field of dermatology, because of its selectivity in ablating vascular and pigmented lesions. Experience with its use in treatment of condylomata acuminata is limited.

Hazards Lasers are hazardous to the patient, operator and staff. Extreme caution in their use will virtually eliminate the attendant risks of retinal and corneal damage, skin burns and fire. There has also been expressed concern about possible airborne transmission of viable fragments of papilloma virus, released during laser surgery. Although the practical significance of this finding is unknown, most operators employ strong suction in the operative field, to eliminate this hazard. Useful guidelines on safe use of lasers in medical practice were published by a DHSS working party in $1985 .^{16}$

Choice of laser in treatment of genital warts Although there is no doubt that laser achieves supremely delicate precision in treating small genital skin lesions, especially when performed under colposcopic control, it is doubtful whether the end results are in practice any better than skilful electrosurgery. Taking into account increased costs and attendant hazards of laser surgery, it is doubtful whether many genitourinary physicians would buy such equipment primarily for treatment of genital warts, but would intend it to have additional purposes. It is likely that choice between a $\mathrm{CO}_{2}$ or ng:YAG laser would depend on what the additional purposes are: most gynaecologists treating CIN choose the $\mathrm{CO}_{2}$ laser, whereas ng:YAG lasers are ideally adapted to urological use, including ablation of intra-urethral warts. In either case, the laser system chosen should be capable of delivering a power output as low as 5 watts, for use on the genital skin.

In summary, choice of equipment for treating genital warts requires that the user should define his or her needs precisely. Equipment which is needlessly complex is more difficult to use, more costly and often becomes embarrassingly redundant. New equipment should complement that already used. Some apparatus demands rigorous safety, servicing, staff training and financial investments; this needs 
careful cost/benefit analysis. It is hoped that this article will facilitate informed choice of appropriate equipment.

The author thanks the following manufacturers for their help in providing technical information for this article. Further information on equipment can be obtained from them, as well as from other suppliers, on request. Pennco Medical Ltd., (Cryounits), 6 South Hill Park, London NW3 2SB. (071) 435-2122. Cryogenic Technology Ltd., (Cryounits), Unit 2, Goods Road, Belper, Derbyshire. DE5 1UU. (0773) 821515. Spembly Ltd., (Cryounits and Laser), Newbury Road, Andover, Hampshire. SP10 4DR. (0264) 65741. Practice Management Systems Ltd., (Cryounits), The Clockhouse, 145B Hughenden Road, High Wycombe, Bucks. HP13 5PN. (0494) 474811. Schuco International Ltd., (Electrosurgical Units), Lyndhurst Avenue, London N12 0NE. (081) 368-1642. Downs Surgical plc, (Electrosurgical Units), Church Path, Mitcham, Surrey. CR4 3UE. (081) 640-3422. Keeler Ltd., (Laser), Clewer Hill Road, Windsor, Berkshire. SL4 4AA. (0753) 857177.

1 Ghosh AK. Cryosurgery of genital warts in cases in which podophyllin treatment failed or was contraindicated. $\mathrm{Br} J$ Venereal Dis 1977;53:49-53.

2 Simmons PD, Langlet F, Thin RNT. Cryotherapy versus electrocautery in the treatment of genital warts. $B r J$ Venereal Dis 1981;57:273-4.

3 Stone KM, Becker TM, Hadgu A, Kraus SJ. Treatment of external genital warts: a randomised controlled trial comparing podophyllin, cryotherapy and electrodesiccation. Genitourin Med 1990;66:16-19.

4 Duus BR, Philipsen T, Christensen JD, Lundvall F, Sondergaard J. Refractory condylomata acuminata: a controlled clinical trial of carbon dioxide laser versus conventional surgical treatment. Genitourin Med 1985;61:59-61.

5 Jensen SL. Comparison of podophyllin application with simple surgical excision in clearance and recurrence of perianal condylomata acuminata. Lancet 1985;331:1146-8.

6 Thomson JPS, Grace RH. The treatment of perianal and anal condylomata acuminata: a new operative technique. $J R$ Soc Med 1978;71:180-5.

7 Gage AA. What temperature is lethal for cells? J Dermat Surg Onc 1979;5:459-60.

8 Bald WB, Fraser J. Cryogenic Surgery. Reports on Progress in Physics 1982;45:1381-434.

9 Torre D. Cryosurgical treatment of epitheliomas using the cone spray technique. J Dermatol Surg Onc 1977;3:432-6.

$10 \mathrm{Zacarian}$ SA. Is lateral spread of freeze a valid guide of depth of freeze? J Dermatol Surg Onc 1978;4:561-3.

11 Pichotka J, Lewis RB. Effect of rapid and prolonged rewarming on local cold injury. United States Armed Forces Medical Journal 1951;2:1293-310.

12 Zacarian S. Cryosurgery for Skin Cancer and Cutaneous Disorders. St Louis, CV Mosby Company, 1985.

13 Ferenczy A. Comparison of cryo- and carbondioxide laser therapy for cervical intraepithelial neoplasia. Obstet Gynecol 1985;6:793-8.

14 Bigrigg MA, Codling BW, Pearson P, Read MD, Swingler GR. Colposcopic diagnosis and treatment of cervical dysplasia at a single clinic visit. Lancet 1990;336:229-31.

15 Prendiville $\mathbb{W}$, Cullimore J, Norman S. Large loop excision of the transformation zone (LLETZ): a new method of management of women with cervical intra-epithelial neoplasia. $\mathrm{Br}$ JObstet Gynaecol 1989;96:1054-60.

16 Department of Health and Social Security. . Guidance on the Safe use of Lasers in Medical Practice. London, Her Majesty's Stationery Office, 1984.

Accepted for publication 31 July 1991 